\title{
What Are the Learning Approaches Applied by Undergraduate Students in English Process Writing Based on Gender?
}

\author{
Arsaythamby Veloo ${ }^{1}$, Hariharan N. Krishnasamy ${ }^{1}$ \& Hana Mulyani Harun ${ }^{1}$ \\ ${ }^{1}$ School of Education and Modern Languages, University Utara Malaysia, Sintok, Kedah, Malaysia \\ Correspondence: Arsaythamby Veloo, School of Education and Modern Language, University Utara Malaysia, \\ 06010 Sintok, Kedah, Malaysia. E-mail: arsay@uum.edu.my
}

Received: January 22, 2015 Accepted: February 23, 2015 Online Published: May 27, 2015

doi:10.5539/ies.v8n6p46

URL: http://dx.doi.org/10.5539/ies.v8n6p46

\begin{abstract}
The purpose of this study is to determine gender differences and type of learning approaches among Universiti Utara Malaysia (UUM) undergraduate students in English writing performance. The study involved 241 (32.8\% male \& 67.2\% female) undergraduate students of UUM who were taking the Process Writing course. This study uses a Two-Factor Study Process Questionnaire (R-SPQ-2F) by Biggs, Kember, and Leung (2001). This instrument assesses how students in higher learning institutions approach learning. In addition, data was also obtained from students' overall performance in the Process Writing course. The overall score for the Process Writing course was $67.58 \%$ in which female scores were above the average score while the scores for males were below the average. Overall, the vast majority of UUM undergraduate students apply the surface approach compared to the deep approach. For the surface approach learning, more students chose the surface strategy when compared to the surface motive. For the deep learning strategy, most students chose the deep strategy compared to the deep motive. Very few students used a combination of both approaches. In the context of English language writing, students need to have an intrinsic interest in what is being discussed for their writing activities. An intrinsic interest will help to make learning meaningful as in the deep learning approach. However, the findings provide evidence that most female students who applied the surface approach managed to score well in their overall performance in Process Writing.
\end{abstract}

Keywords: English writing, gender, learning approach, surface learning, deep learning

\section{Introduction}

English is widely used around the globe and the number of non-native speakers is increasing rapidly. In Malaysia, English is officially recognized as a second language. It has been taught in schools as a second language since Malaysia achieved independence in 1957. Proficiency in English can help Malaysian graduates improve their employment opportunities in the job market (Yong, 2010). Malaysian students can improve their English through formal instruction in the classroom and real life usage. Nevertheless, classroom-based lessons could be more effective if teachers identify and recognize their students' learning approaches. Additionally, teachers will be better positioned to understand the challenges students face in learning English if they are aware of their students' approaches to learn English.

There are three major learning approaches, that is, the surface, deep, or achieving approach. Individuals may adopt any one of the three major learning approaches based on their individual needs or purpose of the learning task. Characteristics of the surface approach include a tendency to regurgitate memorized facts, and a focus on preparation for assessment. However, the surface approach can be a useful starting point or platform to move towards an in-depth understanding of the content (Biggs, 1987; Trigwell \& Shale, 2004).

Individuals who adopt a deep approach tend to engage with the content critically, and make meaningful connections with previously acquired knowledge. Furthermore, they draw upon various principles to synthesize ideas, make relevant connections between factual evidence and conclusions, and examine arguments based on logical premises. However, students might apply the surface approach as an initial step to acquire basic information so that they can progress to have an in-depth understanding of the content (Biggs, 1987; Trigwell \& Shale, 2004). Entwistle (1988) identified these learners as meaning orientation learners who are intrinsically motivated to study and connect the newly acquired knowledge to their daily lives. On the other hand, students with an achievement orientation try to fulfill course requirements and work towards achieving good grades. 
There are also students who are inclined to use a mixed approach, which is a combination of the deep and surface approach (Biggs, 1987; Shale \& Trigwell, 2004). They tend to use the surface approach if it helps to achieve results and use the deep approach when there is a necessity.

Most Malaysian institutions of higher learning are driven by formative and summative assessments based on a syllabus. Students tend to study the pattern of previous assessments and make preparations for the assessments accordingly. This encourages rote memory and superficial learning as students tend to study based on examination requirements so that they get the best possible grade. Students value good grades as they are important to advance their academic or professional career. On the other hand, there are also some assessments that require the application of higher order thinking skills. The challenge to do well in English courses at the tertiary level in Malaysia is to combine both the surface and deep approaches as good performance in English goes beyond the knowledge level in Bloom's taxonomy. Excellent grades in English involve comprehension, application, analysis, creative thinking, critical thinking, synthesis and evaluation (Yong, 2010).

Students in higher learning institutions have to actively engage with the content, and have a deep understanding of the issues that they discuss so that they can come up with the appropriate responses in the courses that they take. A surface approach might not always be sufficient and students would have to take a deep approach to improve their examination scores. The deep approach is necessary when they need to complete the assignments which might include projects, case studies and term essays. Hence, it is crucial for higher educational institutions to focus on higher order thinking skills, improve the critical aspects of teaching and learning and understand students' approaches toward learning (de Lange \& Mavondo, 2004).

\subsection{Problem Statement}

Although there are many generic studies on learning approaches, there is still a dearth of literature based on empirical studies on learning approaches towards English among Malaysian students. The government has formulated policies to improve the standard of English in Malaysia so that Malaysians are better able to face the challenges of globalization in a rapidly advancing world. English is the lingua franca and language of wider communication in fields such as technology, science, economics, communications and international trade. A study of approaches to learning English could contribute useful insights to improve pedagogical practices and teaching approaches so that students are better able to learn English.

Gender issues are becoming more prominent in studies of students' learning of current society in Malaysia. These issues are the consequence of a worldwide growth in the participation rate of women in higher education (Wisker, 1996). In fact, recent statistics from the Student Affairs Department of Universiti Utara Malaysia (UUM) show that the intake of undergraduate students for semester I and II 2011/2012 consists of 3057 female students and 1143 male students. This data seems to support the inference that female students have more positive learning outcomes or achievement rather than male students because students' entrance to higher education institutions is based on their results in nationwide public examinations. The quality of learning outcomes or achievement is highly related with students' approaches to learning (Hasnor et al., 2013).

\subsection{Approaches to Learning}

Central to Marton and Saljo's (1976) student approaches to learning is the underpinning theory that students take an approach based on course requirements and objectives. The two distinctive approaches are categorized under the deep and surface approaches to learning. The paper by Marton and Saljo (1976) has served as a basic frame of reference for the study of students' approaches to learning (Biggs, 1987).

According to Biggs (1987a), two components of students' relationship to academic learning are the students' motive for learning and ensuing strategies for going about learning. Students' motives influence their strategies applied for learning (Biggs, 1992), but contextual or environmental influences in teaching and learning also affect their choice of strategy. Thus, the overall approach to learning depends on two factors: students' motivation and the learning/teaching environment. Students' preferences for the approach to learning and the learning environment are important components of classroom learning that need to be considered before learning takes place (Biggs, 1992). It follows that motives and strategies tend to be congruent with one another and combine to form approaches to learning. Biggs (1987a) uses the terms surface, deep and achieving to describe the three approaches to learning. Each approach comprises a motivation that guides learning and a strategy for the practical implementation of the approach.

The surface approach includes the surface motive and surface strategy. The surface motive aims to fulfill minimum course requirements to pass the course while the surface strategy involves rote memory to answer examination questions. The deep approach involves the deep motive and deep strategy. The deep motive moves 
beyond performance as students are intrinsically motivated and aim to acquire competence in the chosen subjects of study. Deep strategy is guided by a need to find in-depth meaning through wide reading and building upon previously acquired knowledge. The achieving approach involves the approaching motive and achieving strategy. The achieving motive is guided by a competitive mind set to attain the highest possible grades to satisfy the ego needs. The achieving strategy is characterized by the student who acts according to what is expected of an ideal student such as following the syllabus, reading materials suggested in the course and following deadlines (Biggs, 1987b, p. 3). Upon revision, Kember, Biggs, and Leung (2004) came up with a final version which had two factors; deep and surface with four subscales which is the deep motive, deep strategy, surface motive and surface strategy.

\subsection{Learning Approaches and English Writing Performance}

According to Magno (2009), learners may view these two approaches to be useful and relevant in the same way but their consequences are different. In the context of writing a composition in English, the writer makes use of both the deep and surface approach but the deep approach is a useful process in the sense that it is self-regulated. This means that when individuals start to write, all approaches used in the process are functional. Individuals who have a higher interest in the topic written are more able to use effective strategies that facilitate their writing process. On the other hand, being worried of not being able to write well could act as a barrier to apply better strategies in writing.

In relation to English discourse, Lienemann and Reid (2008) stated that individuals use a variety of learning strategies and approaches when they engage in a writing task. Such learning strategies used in writing are planning, idea-generating, self-evaluating, self-monitoring, and reflecting. When individuals start to write essays and other types of English discourses, they also engage in deep approaches to learning. Writers have a deep understanding of what they are writing about, seek further information, become motivated about the content, plan, and organize their thoughts. Thus, strategies and approaches to learning are simultaneously used when engaging in writing tasks.

The deep approach to learning is used in the composing or writing process. The deep approach to learning is adopted by the student according to the kind of learning task they engage in (Marton \& Saljo, 1976). If writing is the learning task, writers perceive the task as requiring organization of thoughts and planning. In the same way, when self-regulation is used in composition writing, specific strategies are used in the writing process. There is a simultaneous interplay of the learning approaches and self-regulation in the writing process (Evans, Kirby, \& Fabrigar, 2003). The use of learning strategies becomes more evident when a second language is used as a medium (Magno, 2009a).

\subsection{Gender and English Writing Performance}

The perception that girls are more successful at language-based activities than boys is not new (Burman, 2008; Zembar \& Blume, 2008; Smith, 2014; Ballantine, 2015) and the trend seems to be evident in current research. Based on research works in educational attainment in the United States, Smith(2014) has observed that high school females outperform high school males in reading and writing. These two language skills are important for academic success.

In comparison, masculine linguistic competences were valued as intellectual capacity manifested in the form of reserved, self-regulated, verbal communicative skills. Current trends in educational research indicate that female achievements receive less attention while male underachievement is highlighted especially when seen within the context of socio economic disadvantages that lead to underachievement among students. Research studies (Delamont, 1999; Smith, 2003) have indicated that a sense of moral panic over male underachievement in language education is not based on academic justification nor examination results as the achievements in examinations between males and females have been consistent since the 70s.

A strong focus on male under performance in the teaching profession (Jones \& Myhill, 2004) links to the commonly held perception that females generally perform better in languages than males and males are less inclined towards writing and learning English. According to Ayodele (2009), many studies in the last few decades have asserted that male students outperformed female students in mathematics and science, with larger differences in science. Generally, female students were positioned as better at written communication than were males. An earlier study by Millard (1997) suggested that girls' reading experiences prepare them better to approximate the writing output required in schools when compared to the males. However, not all studies have a gender bias as other studies have focused on how to motivate students how to write (Roger, 2013). 


\subsection{Gender and Learning Approaches}

Studies conducted previously on gender differences and approaches to learning have not always produced similar results. For example, Biggs (1987a) conducted his study on more than 2,300 students in Australian universities and former CAEs using the SPQ. Biggs found that males scored higher than females on the surface approach but lower than females on the achieving approach. On the contrary, some studies (Byrne et al., 2008) on learning approaches of accounting students have shown that females score significantly higher for the surface learning approach compared to males. These results, however, have not always been consistent with previous studies. For example, Byrne et al. (2008) found that male and female first year accounting students have similar approaches to learning.

According to Byrne and Willis (2008), gender differences on the strategic main scale and a number of the subscales were identified. It is important that educators are aware of these differences when interacting with their students, more so in a pastoral role. Females display a heightened fear of failure and may need encouragement to assess their performance on a more realistic basis. Males are not as effective at managing their time and organising their study and may have greater difficulty adapting to the less guided study environment of a university.

According to Wehrwein, Lujan, and DiCarlo (2006), there is a large body of literature available on gender differences in learning, and providing a comprehensive review of this topic which is beyond the scope of this paper. Briefly, a gender-based preference in learning style is only one area in which males and females are unique. It has been reported that males have a preference for rational evaluation and logic, whereas females use "elaborative" processing in which they tend to seek personal relevance or individual connections with the material being taught (Lie, Angelique \& Cheong, 2004). Males tend to be more achievement oriented, whereas females are more socially and performance oriented (Chang, 2004). Moreover, based on previous research by Lie, Angelique \& Cheong (2004), female students score lower on deep strategies, since they may find it harder to relate some course material to their personal experiences. It is also possible that if the more distinct deep strategies of abstract conceptualization and elaborative processing were studied, then it would be found that males' higher grades reflect an emphasis on learning outcomes associated more with abstract conceptualization than with elaborative processing.

The genders also differ in their beliefs about what is most important to student learning, with females ranking social interaction with other students and self-confidence as higher than males (Brassard, 2004). Additionally, males are likely to attribute their success in the classroom to external causes such as teaching, whereas females generally see their success as being directly related to their efforts in the classroom (Grollino \& Velayo, 1996). This statement suggests that males tend to be more externally focused, but females tend to be more introspective and self-critical.

A research conducted by de Lange and Mavondo (2004) in Australia found no gender differences in the way intrinsic and extrinsic motivation affect surface and deep approaches to learning. This is in contradiction to the widely assumed belief that male students' intrinsic motivation had a positive relationship with surface learning. According to de Lange and Mavondo (2004), this counter-intuitive finding could be attributed to challenges faced by males such as family commitment, although females face similar challenges (Donald \& Jackling, 2007)

All countries take steps to reduce the gap between male and female educational disparities. Recent educational efforts suggest that there has been more focus on low-achieving males in reading. PISA 2000 showed that generally, females performed better than males in reading literacy whereas males performed better than females in mathematics literacy (Donald \& Jackling, 2007).

\section{Method}

This study was conducted in Universiti Utara Malaysia, which is situated in the northernmost state in Malaysia, that is, Kedah. Participants were chosen from those who had enrolled for the Process Writing course. UUM offers three English language courses, and Process Writing (SBLE 2103) is one of the compulsory courses. Regardless of their achievement in prior nationwide examinations, all students need to enroll for this course. This upper intermediate level course aims at helping students to achieve their academic goals, especially in relation to academic writing. The course offers a comprehensive approach to the process of writing from topic and audience considerations to planning, organizing and developing texts.

The population of this study consists of 1,542 undergraduate students in UUM who were enrolled for the Process Writing course. Most of the students in every intake are females and they comprise approximately $70 \%$ of the student population in every intake. From this total of 1,542 undergraduates, 15 classes of students were chosen 
from a total of 70 classes. The targeted sample was chosen via random cluster sampling. According to Gay, Millls, and Airasian (2006) cluster sampling involves the random selection of intact groups, not individuals. All members of the selected groups have similar characteristics. The targeted sample in this study was determined based on Krejcien Morgan (1970) who suggested that the sample size for this population should be 306. From a total of 306 questionnaires distributed to these 15 classes, only 257 were valid. 49 questionnaires could not be used because students gave incomplete information or some vital information like their matric numbers were missing. The matric number helps to retrieve student information such as their scores in examinations. Finally, after the Process Writing results were gathered, there were only 241 samples left. This descriptive data emphasized and highlighted respondents' profile in terms of their gender as the objective of this study was to determine the differences between gender and learning approaches in English writing performance among undergraduate students. The research respondents consisted of 79 male students (32.8\%) and 162 female students (67.2\%). There were $83(34.4 \%)$ more female students than males. This gender difference in numbers reflects the current trend in the student intake in UUM.

The instrument administered in this study is the Revised Two-Factor Study Process Questionnaire (R-SPQ-2F) by Biggs, Kember, and Leung (2001). This instrument is a revised, shortened version of the original SPQ by Biggs (1987). It was developed and designed to assess how students in higher learning institutions approach learning. It was adapted for the purposes of this study in UUM among the undergraduates enrolled for the Process Writing course. The study aims to identify gender differences in English writing performance and learning approaches applied by UUM undergraduate students

\section{Research Findings}

The findings show a difference between the overall performance of the male and female undergraduate students in the Process Writing course. The overall score for the Process Writing course is $67.58 \%$ which is equivalent to a grade B. Grade B is categorized as an average grade. Female students score (68.88\%) higher than the average score for the Process Writing course. On the other hand, males score (64.93) less than the overall average score for the course.

\subsection{Gender and Level of English Writing Performance among UUM Undergraduate Students}

Table 1 shows that the Levene's test was not significant ( $\mathrm{p}>.05$ ). This result assumes equal variance between male and female students in English writing performance. The independent samples t-test showed statistically significant difference $(\mathrm{t}(239)=-3.71, \mathrm{p}<.05, d=0.51)$ and the size effect was moderate. The results indicate that female students $(\mathrm{M}=68.88, \mathrm{SD}=7.09)$ scored better in English writing performance compared to males $(\mathrm{M}=64.93$, $\mathrm{SD}=8.99$ ).

Table 1. Gender and English writing performance

\begin{tabular}{lllllll}
\hline Gender & $\mathrm{N}$ & Mean & $\mathrm{SD}$ & $\mathrm{df}$ & $\mathrm{t}$ & $\mathrm{p}$ \\
\hline Male & 79 & 64.93 & 8.99 & 239 & -3.71 & $.00^{*}$ \\
Female & 162 & 68.88 & 7.09 & & & \\
\hline${ }^{*} \mathrm{p}<.05$ & & & & & &
\end{tabular}

\subsection{Type of Learning Approach Applied by UUM Undergraduate Students}

Table 2 shows that most of the UUM undergraduate students applied the surface learning approach in their learning compared to the deep learning approach. 207 (86\%) students applied the surface learning approach while only $25(10 \%)$ students applied the deep learning approach. Thus, this result shows that most undergraduate students applied the surface learning approach. From the total of 241 undergraduate students, the gender comparison showed that 144 (89\%) female students applied the surface approach compared to the 63 (80\%) male students. Hence, it indicates that more female students applied the surface approach compared to male students. In contrast, $10(13 \%)$ male students applied the deep learning approach while only $15(9 \%)$ female students applied the deep learning approach. Only $9(4 \%)$ of the students applied both the approaches. 
Table 2. Gender and learning approaches among undergraduate students

\begin{tabular}{lcccccccc}
\hline Gender & \multicolumn{2}{c}{ Deep Approach } & \multicolumn{2}{c}{ Surface Approach } & \multicolumn{2}{c}{ Both Approach } & \multicolumn{2}{c}{ Total } \\
\hline & $\mathrm{N}$ & $\%$ & $\mathrm{~N}$ & $\%$ & $\mathrm{~N}$ & $\%$ & $\mathrm{~N}$ & $\%$ \\
\cline { 2 - 9 } Male & 10 & 13 & 63 & 80 & 6 & 7 & 79 & 33 \\
Female & 15 & 9 & 144 & 89 & 3 & 2 & 162 & 67 \\
Total & 25 & 10 & 207 & 86 & 9 & 4 & 241 & 100 \\
\hline
\end{tabular}

Based on Table 3 which shows the relationship between gender and the deep learning approach, most of the students applied the deep strategy compared to the deep motive. From a total of $10 \%$ who applied the deep learning approach, only 10\% (25 students) applied the deep motive while 80\% (191 students) applied the deep strategy. Thus, it shows that most deep approach learners tend to choose the deep strategy rather than the deep motive.

Table 3. Gender and deep learning approaches (deep motive \& deep strategy)

\begin{tabular}{lcccccccc}
\hline \multirow{2}{*}{ Gender } & \multicolumn{2}{c}{ Deep Motive } & \multicolumn{2}{c}{ Deep Strategy } & \multicolumn{3}{c}{ Both Deep Approach } & \multicolumn{2}{c}{ Total } \\
\cline { 2 - 8 } & $\mathrm{N}$ & $\%$ & $\mathrm{~N}$ & $\%$ & $\mathrm{~N}$ & $\%$ & $\mathrm{~N}$ & $\%$ \\
\hline Male & 10 & 13 & 55 & 70 & 14 & 18 & 79 & 33 \\
Female & 15 & 9 & 136 & 84 & 11 & 7 & 162 & 67 \\
Total & 25 & 10 & 191 & 80 & 25 & 10 & 241 & 100 \\
\hline
\end{tabular}

Table 4 shows the relationship between gender and the surface learning approach. Based on the surface learning approach subscales which are surface motive and surface strategy, most of the students applied the surface motive. From the 207 (86\%) students who applied the surface learning approach, 107 (44\%) students chose the surface motive while $82(34 \%)$ students chose the surface strategy. Apart from that, there were $52(19 \%)$ students who chose both the surface motive and surface strategy equally. Thus, most surface approach learners tend to choose the surface motive rather than the surface strategy.

Table 4. Gender and surface learning approaches (surface motive \& surface strategy)

\begin{tabular}{lcccccccc}
\hline \multirow{2}{*}{ Gender } & \multicolumn{2}{c}{ Surface Motive } & \multicolumn{2}{c}{ Surface Strategy } & \multicolumn{2}{c}{ Both Surface Approach } & \multicolumn{2}{c}{ Total } \\
\cline { 2 - 9 } & $\mathrm{N}$ & $\%$ & $\mathrm{~N}$ & $\%$ & $\mathrm{~N}$ & $\%$ & $\mathrm{~N}$ & $\%$ \\
\hline Male & 31 & 39 & 32 & 41 & 16 & 20 & 79 & 33 \\
Female & 76 & 47 & 50 & 31 & 36 & 22 & 162 & 67 \\
Total & 107 & 44 & 82 & 34 & 52 & 22 & 241 & 100 \\
\hline
\end{tabular}

\section{Discussion}

\subsection{Gender and English Writing Performance}

The overall score for the Process Writing course is $67.58 \%$ which earns an average grade of B for the students. Female students scored higher than the overall average score for the Process Writing course. Males, on the other hand, scored below this average. The results indicate that female students scored better in English writing performance compared to males. These results for Process Writing seem to concur with the perception that girls are more successful at language-based activities than boys (Burman, 2008; Zembar \& Blume, 2008). The results seem to fall into a broader pattern in which female students outperform male students in reading and writing, with bigger differences in writing (Battistich, Solomon, Kim, Watson, \& Schaps, 1995; Smith, 2014; Ballantine, 2015). 


\subsection{Gender and Learning Approaches}

Overall, the vast majority of the students applied the surface approach compared to the deep approach. For surface approach learning, more students applied the surface strategy when compared to the surface motive. For the deep learning strategy, most students applied the deep strategy compared to the deep motive. Very few students used a combination of both approaches. The research findings show that most undergraduate students applied the surface learning approach in their learning. This research finding is consistent with other research findings (Magno, 2009) which claimed that the surface approach favors Asian students who are seen as compliant and prefer rote memorization. Though they are being perceived as such, they still manage to be successful and they attribute success to effort rather than ability. Asians view the surface approach to be functional in their learning because it brings about positive outcomes in their examination results.

Based on the research findings, the percentage of male students who applied the deep learning approach was higher than the female students. Nevertheless, the overall percentage of students who applied the deep learning approach was only $10 \%$. This finding is in line with Yong's (2010) research which showed that most Malaysian students were not inclined to use the deep learning approach. Similarly, for the deep motive strategy, the percentage of male students who applied the deep strategy was more than the females. This finding, though, contradicts with Lie, Angelique and Cheong's (2004) research which found no gender differences in deep motive learning. The research findings show that the percentage of females who applied the deep strategy learning approach was higher than the males. This finding is apparently not in line with a study by Lie, Angelique and Cheong (2004) in the National University of Singapore (NUS) which found that male students scored slightly higher than female students in the deep strategy learning. The research findings show that there were gender differences in the surface learning approach. The percentage of female students who applied the surface learning approach was more than the male students. Both male and female students have more or less the same surface strategies in learning in which they tend to limit learning to bare essentials and reproduce them through rote learning. In other words, surface strategy is reproductive in which the focus is on recalling the essential elements of content through rote learning.

\subsection{Implication}

Course work contributes to $60 \%$ of the marks for the English Process Writing course. The coursework has four components. This includes a quiz, a writing portfolio, a collaborative essay and an oral presentation. These components require listening, speaking, reading and writing skills. The activities involve comprehension, arguments, logical reasoning, analysis, synthesis of ideas and making judgments. Finally, Process Writing students will need to sit for a final examination which is allotted $40 \%$ of the overall marks. The written examination consists of structured questions involving the analysis of various elements of essay writing such as the thesis statement, topic sentences and strategies of introduction and conclusion. The second and third parts involve the writing of an expository essay and the writing of an argumentative essay respectively. Though the assessments are designed to promote deep learning and encourage higher order thinking skills, the practical constraints of time to complete the syllabus and assignments encourage surface learning. Moreover, a pass in the Process Writing course is compulsory and students will not be able to graduate if they do not pass. Student records show that most of the students come into the university with an entry point of Band 1, 2 or 3 in a broad ranking nationwide system in which Band 6 represents the highest level of achievement in English in the MUET examination (Malaysian University English Test). Thus, students often have to resort to very strategic learning so that they can meet the demands of the course in 14 weeks. Students can acquire many marks if they apply appropriate strategies to answer the examination questions. Furthermore, students are able to make fairly broad predictions on the questions that will be asked for the summative assessment, as the marking scheme is such that they can score marks for several sections by rote learning and practice. In brief, although a small number of students apply the deep learning approach, male students tend to apply this approach more than female students in their English Process Writing performance. Deep learning promotes understanding and application for life which is important for male and female students.

However, educators can take note that both genders have many shared preferences in their learning approaches. Thus, it is easier for educators to think and plan activities for the students in the classroom as educators do not have to worry much as both students have can cope well with their deep strategy. In fact, most of higher institutions students were inculcated with efficient strategy in their learning during this particular undergraduate level.

A surface approach is likely to occur when students are motivated to fulfill the demands placed on them by others, so it relates more to extrinsic motivation and evaluation anxiety and is particularly sensitive to assessment 
procedures. Learning is regarded as passive transmission of what is found in learning materials to the brain of the learner, with particular emphasis on memorization in knowledge acquisition. In higher learning institutions, most undergraduate students are motivated to fulfill the demands placed by lecturers on them. Most students who are selected to higher learning institutions are those with high enthusiasm to learn, although most of them learn for the sake of passing examinations. Thus, educators need to change their perspective and encourage deep learning within them.

Thus, educators should encourage both male and female students to inculcate deep motive rather than surface motive to achieve higher levels of performance as students' motives influences their strategies of learning. The surface motive will be of limited benefit to students in the long run as the surface motive is instrumental in its orientation and the main purpose is to meet minimum requirements for assessment. The aim of higher learning institutions is not just to produce high achievers but also graduates who can survive in real life situations or ready to join the work force and solve real problems. If the students just meet minimum requirements for assessment, then they are not ready to face the real world challenges. Hence, it is the responsibility of all parties especially educators to enhance their learning and change their surface motive of learning.

To put in a nutshell, surface strategy in learning is of limited benefit for students regardless of their gender and their levels of education. Recalling the essential element of content via rote learning is not advisable as students would easily forget what they memorize. It is better that students learn something via deep understanding, as the content would remain in their mind in the long run. They would be able to apply it well once they graduate and enter the work force.

The implication of the research findings show that students' learning approaches is crucial for them to perform well in English writing. However, the results seem to indicate that the surface approach strategy is dominant. This implies that students tend to remember the bare essentials of what is required in the assessments and reproduce them through rote learning. By extension, it could mean that there is little motivation to read widely or read extensively based on the suggested readings. Secondly, the deep motive shows low scores. This point must be taken into account for pedagogical purposes as a deep motive helps to develop competence in academic subjects. A lack of the deep motive points to a gap between students' level of intrinsic interest and the kind of intrinsic interest required to develop competence in academic writing.

\section{Conclusion}

In the English writing context, writing skill requires the students to have intrinsic interest of what is being discussed in their writing to ensure that their learning is meaningful as offered in the deep learning approach to learn. Yet, from the research findings, most female students who applied the surface approach managed to score well in their overall performance in English writing. This implies that they tend to memorize information, study to pass examinations, and concentrate on topics that were tested. Higher education in Malaysia is still based on reception-based learning. Thus, it has become a major concern for all educators to change this phenomenon in order to produce students who not only score well in examinations, but have a deep understanding of the content and integrate it into their daily lives.

\section{References}

Ayodele, M. O. (2009). Gender Differences in Mathematics and Integrated Science Achievement Among Junior Secondary School Students. Malaysian Journal of Learning \& Instruction, 6, 41-53.

Ballantine, J. H., \& Spade, J. Z. (2015). Schools and Society: A Sociological Approach to Education. Sage Publications: USA.

Biggs, J. B. (1987). Student Approaches to Learning And Studying. Australian Council for Educational Research (ACER).

Biggs, J. B. (1987a). Student approaches to learning and studying. Melbourne: Australian Council for Educational Research.

Biggs, J. B. (1987b). Learning process questionnaire manual. Melbourne: Australian Council for Educational Research.

Biggs, J. B. (1992). Why and how do Hong Kong students learn? Using the Learning and Study Process Questionnaires. Hong Kong: Hong Kong University.

Biggs, J. B., Kember, D., \& Leung, D. Y. P. (2001). The Revised Two Factor Study Process Questionnaire: R-SPQ-2F. British Journal of Educational Psychology, 71(1), 133-149. http://dx.doi.org/10.1348/000709901158433 
Brassard, C. (2004). Are learning patterns different on Mars and Venus? CDTL Brief, 7, 5-6.

Burman, D. D., Bitan, T., \& Booth, J. R. (2008). Sex differences in neural processing of language among children. Neuropsychologia, 46(5), 1349-136. http://dx.doi.org/10.1016/j.neuropsychologia.2007.12.021

Byrne, M., \& Willis, P. (2008). An exploration of tertiary accounting students' prior approaches to learning accounting. International Journal of Management Education, 7(3), 35-46.

Cano, F., \& Berbén, A. B. G. (2009). University students' achievement goals and approaches to learning in mathematics. The British Journal of Educational Psychology, 79(1), 0007-0998. http://dx.doi.org/10.1348/000709908X314928

Case, J., \& Gunstone, R. (2003). Going deeper than deep and surface approaches: A study of students' perceptions of time. Teaching in Higher Education, 8(1), 55-69. http://dx.doi.org/10.1080/1356251032000052320

Chang, W. C. (2004). Learning goals and styles by gender-a study of NUS students. CDTL Brief, 7(1), 4-5.

De Lange, P., \& Mavondo, F. (2004). Gender and motivational differences in approaches to learning by a cohort of open learning students. Accounting Education, 13(4), 431-448. http://dx.doi.org/10.1080/0963928042000306765

Delamont, S. (1999). Gender and the discourse of derision. Research Papers in Education, 14(1), 3-21. http://dx.doi.org/10.1080/0267152990140102

Donald, J., \& Jackling, B. (2007). Approaches to learning accounting: A cross-cultural study. Asian Review of Accounting, 15(2), 100-121. http://dx.doi.org/10.1108/13217340710823341

Entwistle, N. (1988). Motivational factors in students' approaches to learning. In R. R. Schmeck (Ed.), Learning Strategies and Learning Styles (pp. 21-49). New York: Plenum Press.

Gay, L. R., Mills, G. E., \& Airasian, E. (2006). Educational Research: Competences for Analysis and Application. New Jersey: Pearson.

Grollino, E., \& Velayo, R. S. (1996). Gender Differences in the Attribution of Internal Success among College Students. In Annual Convention of the astern Psychological Association (pp. 1-12, Philadelphia, PA).

Hasnor, H. N., Ahmad, Z., \& Nordin, N. (2013). The relationship between learning approaches and academic achievement among INTEC students, UiTM Shah Alam. Procedia-Social and Behavioral Sciences, 90, 178-186. http://dx.doi.org/10.1016/j.sbspro.2013.07.080

Jones, S., \& Myhill, D. A. (2004). Troublesome boys and compliant girls. British Journal of Sociology of Education, 25(5), 557-571.

Kember, D., Biggs, J., \& Leung, D. Y. P. (2004). Examining the multidimensionality of approaches to learning through the development of a revised version of the learning process questionnaire. Educational Psychology Journals, 74(2), 261-279. http://dx.doi.org/10.1348/000709904773839879

Krejcie, R. V., \& Morgan, D. W. (1970). Determining sample size for research activities. Educational and Psychological Measurement, 30, 607-610.

Lie, L. Y., Angelique, L., \& Cheong, E. (2004). How do male and female students approach learning at NUS. CDTL Brief, 7(1), 1-3.

Lienenmann, T. O., \& Reid, R. (2008). Using self-regulated strategy development to improve expository writing students with attention deficit hyperactivity disorder. Reston, 74(4), 471-486.

Magno, C. (2009). Self-regulation and approaches to learning in English composition writing. TESOL Journal, 1(1), 1-16.

Magno, C. (2009a). Investigating the effect of school ability on self-efficacy, learning approaches and metacognition. The Asia-Pacific Education Researcher, 18(2), 233-244.

Marton, F., \& Saljo, R. (1976). On qualitative differences in learning: I-Outcome and process. British Journal of Educational Psychology, 46(1), 4-11. http://dx.doi.org/10.1111/j.2044-8279.1976.tb02980.x

Millard, E. (1997). Differently literate: Boys, girls and the schooling of literacy. London, UK: Falmer.

Roger, B., Michael, D., Douglas F. K., Courtney, M., \& Sharon, Z. (2013). Examining dimensions of self-efficacy for writing, Journal of Educational Psychology, 105(1), 25-38. http://dx.doi.org/10.1037/a0029692

Smith, E. (2003). Understanding underachievement: An investigation into the differential attainment of 
secondary school pupils. British Journal of Sociology of Education, 24(5), 575-586. http://dx.doi.org/10.1080/0142569032000127143

Smith, T. M. (2014). Educational Achievement and Attainment in the United States. In D. Levinson, P. Cookson, \& A. Sadovnik (Eds.), Education and Sociology: An Encyclopedia (pp 181-189). Routledge: USA.

Trigwell, K., \& Shale, S. (2004). Student learning and the scholarship of university teaching. Studies in Higher Education, 29(4), 523-536. http://dx.doi.org/10.1080/0307507042000236407

Wehrwein, E. A., Lujan, H., L., \& DiCarlo, S. E. (2006). Gender differences in learning style preferences among undergraduate physiology students. Advances in Physiology Education, 31(2), 153-157. http://dx.doi.org/10.1152/advan.00060.2006

Wisker, G. (1996). Empowering women in higher education. London : Kogan Page

Yong, F. L. (2010). A Study on the Learning Approaches of Malaysian Students in Relation to English Language Acquisition. American Journal of Scientific Research, 9, 5-11.

Zember, M. J., \& Blume, L. B. (2008). Middle Childhood Development: A Contextual Approach. Pearson: London.

\section{Copyrights}

Copyright for this article is retained by the author(s), with first publication rights granted to the journal.

This is an open-access article distributed under the terms and conditions of the Creative Commons Attribution license (http://creativecommons.org/licenses/by/3.0/). 